\title{
Inhibition of p25/Cdk5 Attenuates Tauopathy in Mouse and iPSC Models of Frontotemporal Dementia
}

\author{
Jinsoo Seo, ${ }^{1,2 \star}$ Oleg Kritskiy, ${ }^{1 \star}$ L. Ashley Watson, ${ }^{1,2}$ Scarlett J. Barker, ${ }^{1,2}$ Dilip Dey, ${ }^{1}$ Waseem K. Raja, ${ }^{1,2}$ Yuan-Ta Lin, ${ }^{1,2}$ \\ Tak Ko, ${ }^{1}$ Sukhee Cho, ${ }^{1}$ Jay Penney, ${ }^{1,2}$ @M. Catarina Silva, ${ }^{3}$ CSteven D. Sheridan, ${ }^{3}$ Diane Lucente, ${ }^{4}$ James F. Gusella, ${ }^{4}$

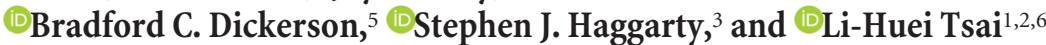 \\ ${ }^{1}$ Picower Institute for Learning and Memory, Massachusetts Institute of Technology, Cambridge, Massachusetts 02139, ${ }^{2}$ Department of Brain and Cognitive \\ Sciences, Massachusetts Institute of Technology, Cambridge, Massachusetts 02139, ${ }^{3}$ Center for Genomic Medicine, Chemical Neurobiology Laboratory, \\ Departments of Neurology and Psychiatry, Massachusetts General Hospital and Harvard Medical School, Boston, Massachusetts 02114, ${ }^{4}$ Molecular \\ Neurogenetics Unit, Center for Genomic Medicine, Massachusetts General Hospital and Harvard Medical School, Boston, Massachusetts 02114, \\ ${ }^{5}$ Massachusetts General Hospital Frontotemporal Disorders Unit, Gerontology Research Unit, and Alzheimer's Disease Research Center, Department of \\ Neurology, Massachusetts General Hospital and Harvard Medical School, Charlestown, Massachusetts 02129, and ${ }^{6}$ Broad Institute of Harvard and \\ Massachusetts Institute of Technology, Cambridge, Massachusetts 02142
}

Increased p25, a proteolytic fragment of the regulatory subunit p35, is known to induce aberrant activity of cyclin-dependent kinase 5 (Cdk5), which is associated with neurodegenerative disorders, including Alzheimer's disease. Previously, we showed that replacing endogenous p35 with the noncleavable mutant $\mathrm{p} 35(\Delta \mathrm{p} 35)$ attenuated amyloidosis and improved cognitive function in a familial Alzheimer's disease mouse model. Here, to address the role of $\mathrm{p} 25 / \mathrm{Cdk} 5$ in tauopathy, we generated double-transgenic mice by crossing mice overexpressing mutant human tau (P301S) with $\Delta$ p35KI mice. We observed significant reduction of phosphorylated tau and its seeding activity in the brain of double transgenic mice compared with the P301S mice. Furthermore, synaptic loss and impaired LTP at hippocampal CA3 region of $P 301 S$ mice were attenuated by blocking p 25 generation. To further validate the role of p25/Cdk5 in tauopathy, we used frontotemporal dementia patient-derived induced pluripotent stem cells (iPSCs) carrying the Tau P301L mutation and generated P301L: $\Delta \mathrm{p} 35 \mathrm{KI}$ isogenic iPSC lines using CRISPR/Cas9 genome editing. We created cerebral organoids from the isogenic iPSCs and found that blockade of p25 generation reduced levels of phosphorylated tau and increased expression of synaptophysin. Together, these data demonstrate a crucial role for $\mathrm{p} 25 / \mathrm{Cdk} 5$ in mediating tau-associated pathology and suggest that inhibition of this kinase can remedy neurodegenerative processes in the presence of pathogenic tau mutation.

Key words: Alzheimer's disease; cerebral organoids; cyclin-dependent kinase 5; iPSCs; isogenic; tauopathy

\section{Significance Statement}

Accumulation of p25 results in aberrant Cdk5 activation and induction of numerous pathological phenotypes, such as neuroinflammation, synaptic loss, $\mathrm{A} \beta$ accumulation, and tau hyperphosphorylation. However, it was not clear whether p25/Cdk5 activity is necessary for the progression of these pathological changes. We recently developed the $\Delta p 35 K I$ transgenic mouse that is deficient in p25 generation and Cdk5 hyperactivation. In this study, we used this mouse model to elucidate the role of p25/Cdk5 in FTD mutant tau-mediated pathology. We also used a frontotemporal dementia patient-derived induced pluripotent stem cell carrying the Tau P301L mutation and generated isogenic lines in which p35 is replaced with noncleavable mutant $\Delta$ p35. Our data suggest that p25/Cdk5 plays an important role in tauopathy in both mouse and human model systems.

\section{Introduction}

Tau is a microtubule-binding protein, which stabilizes and promotes assembly of microtubules. Hyperphosphorylation, insolubilization, and accumulation of tau are observed in various neurodegenerative diseases, including Alzheimer's disease

This work was supported by National Institutes of Health Grant R37NS051874, Robert A. and Renee E. Belfer Family Foundation, and Belfer Neurodegeneration Consortium to L.-H.T., National Institutes of Health/National Institute of Neurological Disorders and Stroke Grant R21NS085487 to S.J.H. and B.C.D., Association for Frontotemporal Degeneration to M.C.S., and Tau Consortium to S.J.H. We thank all members of L.-H.T. laboratory for advice and discussion; and Ting Fu for technical assistance with iPSC reprogramming. 
(AD) and frontotemporal dementia (FTD). Tau hyperphosphorylation can lead to a conformational change of the protein that triggers its dissociation from microtubules and reduced microtubule integrity. The breakdown of this tubular system disrupts intracellular organelle transport, such as the movement of mitochondria or other cargos to peripheral regions, which eventually results in the degeneration of axons (Mazanetz and Fischer, 2007; Kolarova et al., 2012; Kondadi et al., 2014). Abnormal phosphorylation of tau also leads to its mislocalization to dendritic spines, resulting in synaptotoxicity through the abnormal recruitment of tau-binding proteins, such as a Fyn kinase into the synapse (Ittner et al., 2010).

Cyclin-dependent kinase 5 (Cdk5) is a serine/threonine kinase whose activity is necessary for neuronal migration, synapse development, and synaptic plasticity. C $\mathrm{dk} 5$ is not catalytically active unless it is associated with a regulatory activator, such as $\mathrm{p} 35$. The abundance of $\mathrm{p} 35$ is regulated by two alternate pathways consisting of the rapid proteasomal degradation of $\mathrm{p} 35$, or the direct truncation of p35 to a soluble $25 \mathrm{kDa}$ form (p25) by calpain, $\mathrm{a} \mathrm{Ca}^{2+}$-dependent cysteine protease. Whereas the former is common under physiological conditions, the latter is primarily associated with the function of Cdk5 under pathological conditions (Patrick et al., 1999; Ahlijanian et al., 2000; Kusakawa et al., 2000; Lee et al., 2000; Nath et al., 2000).

To date, a large body of literature supports the role of Cdk5 in numerous pathological phenotypes in neurodegenerative disorders, including AD. For example, work in various neurodegenerative disease model systems or animal models of $\mathrm{AD}$ showed that pharmacological inhibition or targeted knockdown of Cdk5 relieved neurotoxicity and tau pathology (Piedrahita et al., 2010; Zhang et al., 2013a; Miller et al., 2015). The ability of Cdk5 to phosphorylate tau (pTau) was shown to be enhanced in the presence of p25 compared with p35 (Van den Haute et al., 2001; Hashiguchi et al., 2002; Noble et al., 2003). Consistent with these findings, several p25-overexpressing transgenic mouse models exhibit tau hyperphosphorylation and aggregation (Cruz et al., 2003; Noble et al., 2003). Together, these studies show that p25/ Cdk5 induces tauopathy.

A recent study reported that $\mathrm{p} 25$ expression is increased in the brain of JNPL3 mice carrying a human mutant transgene harboring a P301L mutation. Inhibition of calpain reduced p25 levels and attenuated tauopathy in these mice (Rao et al., 2014). It suggests that, in addition to p25/Cdk5 inducing tauopathy, p25 production can itself be regulated by pathogenic tau. The novel question that we have not yet answered is whether or not p25 generation is a key factor in developing pathogenic tau mutationinduced pathology. Furthermore, it remains unclear whether p25/Cdk5 mediates tauopathy in patient-derived cell models. Recently, we developed the knock-in mouse $(\Delta \mathrm{p} 35 \mathrm{KI})$ incapable of generating p25 (Seo et al., 2014). In this work, we thoroughly characterized the $\Delta p 35 \mathrm{KI}$ mouse through biochemical, electrical, and behavioral assays. We did not observe any difference in Cdk5 activity between WT and $\Delta p 35 \mathrm{KI}$ mice, which is consistent with the fact that expression of p25 under basal conditions is low. These mice exhibit impaired LTD in hippocampal Schaffer collateral-CA1 synapses and a deficit in memory extinction, sug-

\footnotetext{
The authors declare no competing financial interests.

*J.S. and 0.K. contributed equally to this work.

Correspondence should be addressed to Dr. Li-Huei Tsai, Picower Institute for Learning and Memory, Massachusetts Institute of Technology, Cambridge, MA 02139. E-mail: Ihtsai@mit.edu.

DOI:10.1523/JNEUROSCI.0621-17.2017

Copyright $\odot 2017$ the authors $\quad 0270-6474 / 17 / 379918-08 \$ 15.00 / 0$
}

gesting the role of activity-induced p25 in memory process. However, overall, they display normal brain development, synapse density, locomotion, and learning behavior. And no obvious pathological phenotype was observed in $\Delta p 35 K I$ mice. In the current study, we use this mouse line to inhibit p25 generation in a mouse model of FTD.

Previous studies using isogenic human induced pluripotent stem cells (iPSCs) derived from AD, FTD or Down syndrome individuals have shown that these cells display a number of readily observable disease phenotypes (Israel et al., 2012; Mou et al., 2012; Fong et al., 2013; Zhang et al., 2013b; Silva et al., 2016). The iPSC model system provides a critically needed means by which to conduct mechanistic studies in living human cells. Moreover, the advent of the clustered regularly interspaced short palindromic repeats (CRISPR) system, using the Cas9 nuclease to induce guided DNA breaks, provides a major advance in our ability to manipulate the human genome (Komor et al., 2017). Last, 3D human neural culture systems, also known as cerebral organoids, have been recently developed to better recapitulate some specific features of the human brain, such as architectural complexity and cortical layer formation. We recently found that cerebral organoids derived from familial AD patient iPSCs endogenously develop $A \beta$ and tau aggregation, which has not been observed in conventional 2D culture systems (Raja et al., 2016). In the current study, we generated $\Delta \mathrm{p} 35 \mathrm{KI}$ iPSCs from fibroblasts of an FTD patient by reprogramming along with genome editing techniques, which enabled us to address the role of p25/Cdk5 in a human tauopathy model.

\section{Materials and Methods}

Animals

All animal experiments were performed with approval from the Massachusetts Institute of Technology Committee on Animal Care. P301S Tg mice (PS19) (Yoshiyama et al., 2007) were obtained from the The Jackson Laboratory (https://www.jax.org/strain/008169) and crossed to the $\Delta p 35 K I$ mouse to generate P301S; $\Delta$ p35KI mice. Four-month-old littermates were used for all the experiments, if not otherwise indicated. Male mice were used for electrophysiology experiments, and female mice were used for all biochemistry experiments.

\section{Immunoblot analysis}

Hippocampal or cortical tissues were homogenized in RIPA buffer (50 mm Tris, pH 8.0, $150 \mathrm{~mm} \mathrm{NaCl}, 1 \% \mathrm{NP}-40,0.5 \%$ sodium deoxycholate, $0.1 \%$ SDS) containing protease and phosphatase inhibitors. For organoids, 3 or 4 organoids were pooled, homogenized, and sonicated in RIPA buffer. Lysates were incubated on ice for $15 \mathrm{~min}$ and spun at 12,000 $\mathrm{rpm}$ for $15 \mathrm{~min}$. Then, supernatants were transferred to new tubes and analyzed for protein concentration (Bio-Rad Protein Assay). SDS buffer was added to equal amounts of protein and subjected to SDS-PAGE and immunoblotting analysis.

\section{Antibodies}

Antibodies are as follows: p35 (laboratory of L.-H.T.), Cdk5, HA, GAPDH (Santa Cruz Biotechnology), pTau T181, pTau S202 (Cell Signaling Technology), synaptophysin (Sigma-Aldrich), NeuN (Synaptic Systems), and Tau5 (Thermo Fisher Scientific).

\section{Immunoprecipitation-linked kinase assay}

Hippocampal lysates were incubated with an anti-Cdk5 antibody overnight at $4^{\circ} \mathrm{C}$, and the immunocomplex was subjected to a Cdk5 kinase assay as described previously (Seo et al., 2014).

\section{Immunohistochemistry}

Mice were transcardially perfused with $4 \%$ PFA in PBS under anesthesia (2:1 of ketamine/xylazine), and the brains were sectioned at $40 \mu \mathrm{m}$ thickness with a VT1000S vibratome (Leica). Slices were permeabilized with blocking solution containing $0.1 \%$ Triton X-100, 1 m glycine, $10 \%$ don- 
key serum, and 2\% BSA in PBS for $1 \mathrm{~h}$ at room temperature, and incubated at $4^{\circ} \mathrm{C}$ for overnight with blocking solution containing primary antibody. Slices were then incubated at room temperature for $1 \mathrm{~h}$ with fluorescently conjugated secondary antibodies (Invitrogen), and nuclei were stained with Hoechst 33342 (Invitrogen).

\section{Microscopy}

All images were captured using a Zeiss LSM 880 confocal microscope and the ZEN software, and analyzed using the ImageJ software (National Institutes of Health, https://imagej.nih.gov/ij/, RRID:SCR_003070).

\section{Tau seeding activity assay}

Brains were homogenized in $1 \times$ TBS supplemented with protease inhibitors using a probe sonicator ( $30 \%$ power; 15 pulses). After sonication, the lysates were centrifuged at $16,000 \times g$ for 15 min to eliminate large, insoluble material. The supernatant was stored at $-80^{\circ} \mathrm{C}$ and used for all future experiments. Protein concentration was determined using a BioRad Protein Assay Kit. Fluorescence resonance energy transfer (FRET) biosensor cell lines described previously (Holmes et al., 2014) were provided by Marc I. Diamond. Cells were grown in DMEM (Invitrogen) augmented with $10 \% \mathrm{FBS}$ and $1 \times$ penicillin/streptomycin and maintained at $37^{\circ} \mathrm{C}$ and $5 \% \mathrm{CO}_{2}$ in a humidified incubator. For the assay, cells were plated in a 96-well plate at a density of 40,000 cells/well. Sixteen hours later, at $50 \%$ confluence, brain homogenate samples were transduced into cells using $1 \mu \mathrm{l}$ Lipofectamine/well. After a $48 \mathrm{~h}$ incubation at $37^{\circ} \mathrm{C}$, cells were harvested with $0.25 \%$ trypsin and fixed in $4 \%$ PFA (Electron Microscopy Services) for $15 \mathrm{~min}$, and then resuspended in PBS. An LSR II HST-2 flow cytometer was used to measure the FRET signal within each cell. FRET quantification was accomplished using FlowJo version 10 software (TreeStar). Integrated FRET density was derived by multiplying the percentage of FRET-positive cells in each sample by the median FRET intensity of those cells.

\section{Electrophysiology}

Hippocampal slices (transverse, $400-\mu \mathrm{m}$-thick) were prepared in icecold dissection buffer (in $\mathrm{mm}$ as follows: 211 sucrose, $3.3 \mathrm{KCl}, 1.3$ $\mathrm{NaH}_{2} \mathrm{PO}_{4}, 0.5 \mathrm{CaCl}_{2}, 10 \mathrm{MgCl}_{2}, 26 \mathrm{NaHCO}_{3}$, and 11 glucose) using a VT1000S vibratome (Leica). Slices were then moved to the submerged chamber with $95 \% \mathrm{O}_{2} / 5 \% \mathrm{CO}_{2}$-saturated ACSF consisting of $(\mathrm{mM})$ as follows: $124 \mathrm{NaCl}, 3.3 \mathrm{KCl}, 1.3 \mathrm{NaH}_{2} \mathrm{PO}_{4}, 2.5 \mathrm{CaCl}_{2}, 1.5 \mathrm{MgCl}_{2}, 26$ $\mathrm{NaHCO}_{3}$, and 11 glucose at $30^{\circ} \mathrm{C}$ for at least $1 \mathrm{~h}$ before the recording. Extracellular recording at mossy fiber-CA3 synapses was performed as previously described (Siegert et al., 2015). In brief, a tungsten bipolar electrode was placed in the dentate granule cell layer to stimulate mossy fibers, and extracellular recordings were made in the stratum lucidum of CA3 using a glass microelectrode filled with ACSF (resistance of 2-3 $\mathrm{M} \Omega$ ). LTP was induced by three trains of high-frequency stimulation $(100 \mathrm{~Hz}$ for $1 \mathrm{~s}$ ) with $10 \mathrm{~s}$ intervals after observation of stable baseline. To verify mossy fiber inputs, $1 \mu \mathrm{M}\left(2 \mathrm{~S}, 2^{\prime} \mathrm{R}, 3^{\prime} \mathrm{R}\right)-2-\left(2^{\prime}, 3^{\prime}\right.$ dicarboxycyclopropyl)glycine (Tocris Bioscience), a Group II metabotropic glutamate receptor agonist that selectively blocks mossy fiber responses, was applied at the end of each recording. The amplitude of field EPSPs (fEPSPs) was measured to quantify the strength of synaptic transmission. A MultiClamp 700B amplifier and a Digidata 1440A A-D converter (Molecular Devices) were used for data acquisition and data were analyzed with pClamp10 (Molecular Devices).

\section{iPSC cultures}

FTD patient (Tau P301L carrier) and related healthy individual dermal fibroblasts were generated from a skin biopsy from subjects within the Massachusetts General Hospital Frontotemporal Dementia Clinic as part of the Massachusetts General Hospital Neurodegeneration Repository. Approval for human subject work was obtained under a Partners/ Massachusetts General Hospital-approved Institutional Review Board Protocol (\#2010P001611/MGH). iPSCs (Tau-P301L MGH-2046 and nonmutant control MGH-2069) were generated using a synthetic modified mRNA-based reprogramming method (StemGent mRNA Modified Reprogramming Kit). These iPSC lines have been fully characterized, and presence of the P301L mutation in MAPT was confirmed by sequencing (data not shown). iPSCs were cultured on irradiated mouse embryonic fibroblasts (MEFs, MTI-GlobalStem) in DMEM/F12, HEPES media (Invitrogen) supplemented with $20 \%$ knock-out serum replacement (Invitrogen), $1 \times$ nonessential amino acids, $1 \times$ GlutaMAX (Invitrogen) $\beta$-fibroblast growth factor (PeproTech), and $0.1 \mathrm{~mm} 2$-mercaptoethanol (Sigma-Aldrich) and maintained at $37^{\circ} \mathrm{C}$ and $5 \% \mathrm{CO}_{2}$ in a humidified incubator.

\section{Generation of $\Delta p 35 K I$ isogenic lines}

Preparation of the CRISPR/Cas9-p35-sgRNA plasmid. A sgRNA for targeting CDK5R1 gene (GGGGCTGGGCGAATGTGGAC, reverse) was designed by http://crispr.mit.edu. Both sgRNA and repair template (ssODNs: TGAGGGGCTTTCTTGACTGAGGAGGAGCCCCCGGTC TGGGAACCCGAGAGCTGGCTGGCCGGGGGTGCAGGCGGCTGG GCCGGTGGGGGCTGGAGGCACGACAGCGACTTCTTCAGGTTC TCATTGTTGAGGTGCGTGATGTTGTTCTGGTAGCTGCTGTTGGG CTGCACCTTCTTGGAGTTCTTCTTCTTGG) were synthesized by Integrated DNA Technologies. The CRISPR/Cas9 plasmid (pSpCas9-2AGFP, PX458) was purchased from Addgene, and the p35-sgRNA was cloned into the plasmid as described previously (Ran et al., 2013).

Electroporation. iPSCs on MEFs plates were dissociated with Accutase (Thermo Fisher Scientific) and collected to a $15 \mathrm{ml}$ Falcon tube. Cells were washed with hES media once and then resuspended with hES media to count the number of cells. A total of 5 million cells were transferred to a new tube, and media was removed. Then, the CRISPR/Cas9-p35sgRNA and ssODNs were added to cells, mixed, and transferred to a cuvette. The Nucleofector (Amaxa) and the Human Stem Cell Nucleofector Kit 1 (Lonza) were used for the electroporation, and the cells were resuspended in hES media with $10 \mu \mathrm{M}$ Rho-associated protein kinase inhibitor and transferred to new MEF plates.

Fluorescence-activated cell sorting (FACS). Two days after the electroporation, cells were dissociated with Accutase and transferred to a $15 \mathrm{ml}$ Falcon tube. Cells were washed with hES media once, resuspended with DPBS, and filtered using Falcon polystyrene test tube (\#2235). Filtered cells were collected and sorted by a BD Biosciences Aria II based on GFP signal. Sorted cells were then collected in hES media with $1 \times$ penicillin/ streptomycin and $10 \mu \mathrm{M}$ Rho-associated protein kinase inhibitor (Y27632, Millipore) and plated at a density of 80,000 cells/well.

Colony inspection. Once colonies formed, single colonies were transferred to each well of 12-well MEF plates. After second transfer, cells in the original plates were dissociated and genomic DNAs were extracted as previously described (Ran et al., 2013). PCR was performed with the primer set to target the CDK5R1 gene (p35F-CTGTCCCTGTCTCCCA GCTA, p35R-GGCAGAGAAACTCACCCAGG), and the PCR product was submitted to Genewiz for the sequencing.

\section{Organoid culture}

Organoids were created from iPSCs carrying the Tau P301L mutation, the $\Delta \mathrm{p} 35 \mathrm{KI}$ isogenic, or healthy control lines using the protocol described previously (Raja et al., 2016). In brief, embryoid bodies were formed by loading 12,000 iPSCs per well into 96-well plates precoated with pluronic acid (1\%, F-127, Sigma-Aldrich). Embryoid bodies maintained in the Media 1 consist of Glasgow-MEM supplement with $20 \%$ knock-out serum replacement, $1 \times$ sodium pyruvate, $1 \times$ nonessential amino acids, $0.1 \mathrm{~mm} 2$-mercaptoethanol, $20 \mu \mathrm{M}$ Rho-associated protein kinase inhibitor (Y-27632, Millipore), $5 \mu \mathrm{M}$ TGF $\beta$-inhibitor (SB431532, Tocris Bioscience), and $3 \mu \mathrm{M}$ Wnt-inhibitor (IWRe1, Tocris Bioscience) for $20 \mathrm{~d}$. Dorsomorphin, a BMP inhibitor ( $2 \mu \mathrm{M}$ Tocris Bioscience), was added for the first $3 \mathrm{~d}$. Organoids were then transferred to nonadherent Petri dishes and cultured in Media 2, consisting of DMEM/F12 supplemented with $1 \times$ Chemically Defined Lipid Concentrate and $1 \times$ N2supplement with $40 \% \mathrm{O}_{2} / 5 \% \mathrm{CO}_{2}$ to promote neuroepithelial formation. From day 35, $5 \mu \mathrm{M}$ heparin (Sigma-Aldrich), 10\% FBS, and 1\% Matrigel (Invitrogen) were added to the medium.

\section{Experimental design and statistical analysis}

Data are mean \pm SEM and were analyzed by Prism 6 software (GraphPad). Student's $t$ test was used to compare the means of two groups. One-way ANOVA followed by Tukey's post hoc analysis was used for multiple comparison. $p<0.05$ was considered significant. 


\section{Results}

Abnormal p25 expression induces hyperactivation of Cdk5 in the brain of P301S mice

To first test whether $\mathrm{p} 25$ levels are affected by pathogenic tau, we used a C-terminal specific p35 antibody to detect both p35 and p25 species in the brain of P301S transgenic mice. Using hippocampal lysates from 4-month-old mice, we observed a twofold increase in p 25/p35 ratio in P301S mice compared with that of WT (Fig. $1 A, B ; p=0.030$ ). To measure Cdk5 activity in these samples, we immunoprecipitated $\mathrm{Cdk} 5$, then performed a kinase assay using radiolabeled ATP and histone $\mathrm{H} 1$ protein, as a substrate of Cdk5. We found that basal Cdk5 activity in P301S mouse hippocampus is significantly increased compared with WT (Fig. $1 C ; p=$ 0.0009 by ANOVA). To address the effect of p25 generation on aberrant Cdk5 activation in the P301S mouse brain, we crossed P301S mice with $\Delta p 35 K I$ mice, in which endogenous p35 is replaced with cleavage resistant mutant p35 incapable of p25 generation (Seo et al., 2014). As expected, p25 was undetected in P301S; $\Delta p 35 K I$ mice hippocampal lysates (Fig. $1 A, B)$. The expression of mutant $\Delta \mathrm{p} 35$ protein tagged with triple HA was confirmed by immunoblotting with an anti-HA antibody (Fig. 1A). We then examined Cdk5 activity in these mice and found that inhibition of p 25 generation normalized Cdk5 activity in P301S mice to the levels of WT (Fig. 1C). These data indicate that hyperactivation of Cdk5 in P301S mouse brains is mediated by abnormal p25 generation.

\section{Blockade of p25 generation attenuates tauopathy in P301S mice brain}

Overexpression of human P301S mutant tau was shown to induce tau pathology, including hyperphosphorylation of tau, increased levels of insoluble tau, and the formation of neurofibrillary tangles (Yoshiyama et al., 2007). Although the precise mechanisms of mutant-driven tau hyperphosphorylation remain unclear, a conformational change induced by such mutations is proposed to trigger phosphorylation of other residues of tau by various kinases, such as Cdk 5 or GSK-3 $\beta$, or inhibit dephosphorylation mediated by phosphatases (Mazanetz and Fischer, 2007; Kolarova et al., 2012). To address the contribution of $\mathrm{p} 25 / \mathrm{Cdk} 5$ to tau hyperphosphorylation in P301S mouse brains, we performed immunohistochemistry with hippocampal slices from P301S mice, P301S; $\Delta$ p35KI mice, and their WT littermates. We observed significant reduction of pTau levels in the hippocampus from P301S; $\Delta p 35 K I$ mice compared with those from P301S mice (Fig. 2A). With antibodies against two different pTau epitopes (pTau T181 and pTau S202), we performed Western blotting; consistent with our immunostaining data, levels of pTau in hippocampal lysates from P301S; $\Delta$ p35KI mice were significantly reduced compared with those of $P 301 S$ mice, without changes in total levels of tau (Fig. $2 B ; p=0.0097$ for pTau T181, $p=0.0396$ for $\mathrm{pTau}$ S202, $p=0.283$ for Tau5).
P301S; P301S;

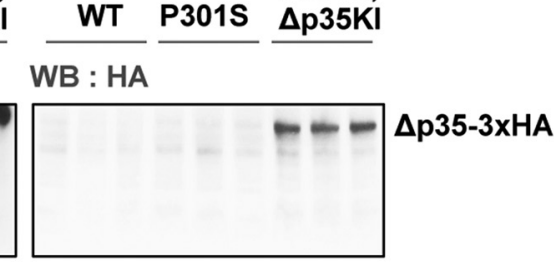

APDH
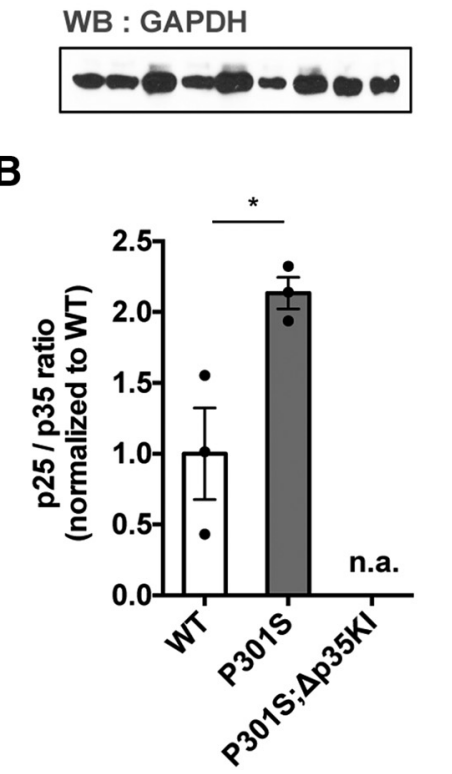

C

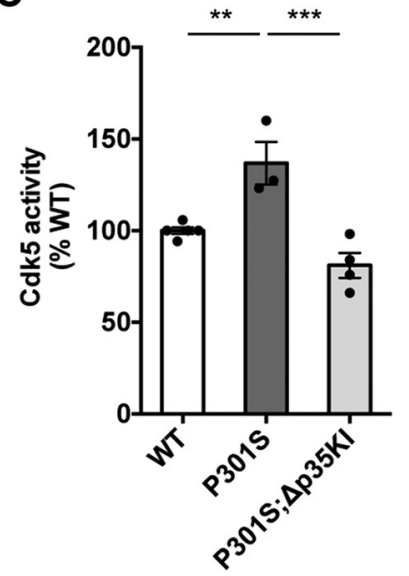

Figure 1. Inhibition of p25 generation abolishes Cdk5 hyperactivation in P3015 mice brain. $\boldsymbol{A}$, Levels of p25 in WT, P301S, and P3015; $\Delta$ p35KI hippocampus. $\Delta$ p35 expression in P3015; $\Delta$ p35KI was confirmed by immunoblotting with an anti-HA antibody. *Nonspecific background band. B, Bar graph represents relative immunoreactivity of p25/p35 compared with WT (Student's $s$ test). ( ( $n=3-5$ per group; $p=0.0009$ by ANOVA). ${ }^{*} p<0.05$ (Student's $t$ test or Tukey's post hoc analysis). ${ }^{* *} p<0.01$ (Student's $t$ test or Tukey's post hoc analysis). ${ }^{* *} p<0.001$ (Student's $t$ test or Tukey's post hoc analysis). Error bars indicate \pm SEM.

Recent studies suggest that pathogenic tau seeds can spread across the brain and trigger tauopathy in regions it spreads toward (Clavaguera et al., 2009; Frost et al., 2009; de Calignon et al., 2012). Thus, we asked whether a reduction of phosphorylated tau by $\mathrm{p} 25 / \mathrm{Cdk} 5$ inhibition affects tau seeding activity in P301S mouse brains. To measure tau seeding activity, we used a FRETbased flow cytometry biosensor assay reported recently (Holmes et al., 2014). This study showed that tau seeding activity of lysates from $P 301 S$ mice could be detected as early as 2 months of age. Therefore, we prepared biosensor HEK293T cells (expressing P301S mutant tau fused to either CFP or YFP) and treated them with brain lysates from 2-month-old P301S, P301S; $\Delta$ p35KI, or WT littermate mice. After $24 \mathrm{~h}$, we measured FRET signals corresponding to the formation of tau aggregates and found that, while tau seeding remained significantly elevated relative to WT brain lysates, inhibition of p 25 production significantly reduced the seeding activity of $P 301 S$ brain lysates (Fig. $2 C$; $p<0.0001$ by ANOVA). Together, these data suggest that aberrant Cdk5 activity by $\mathrm{p} 25$ generation elevates tau hyperphosphorylation and increases tau seeding activity in P301S mouse brain.

\section{Inhibition of $\mathrm{p} 25$ restores synaptic function at mossy fiber-CA3 synapses in P301S mice}

Hyperphosphorylation and aggregation of tau are associated with synapse loss and cognitive impairment, and a significant reduction of synaptic density was observed in the hippocampal CA3 
A

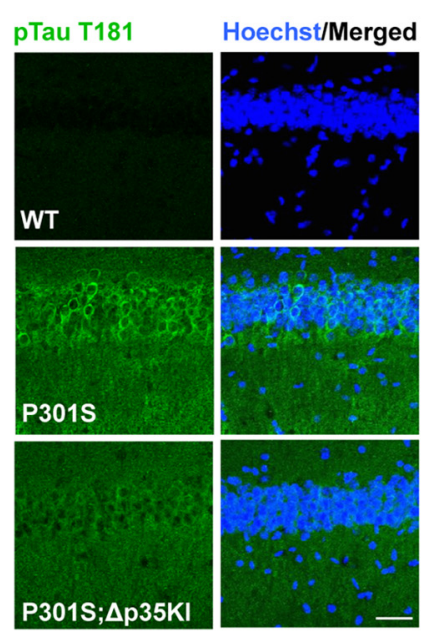

B

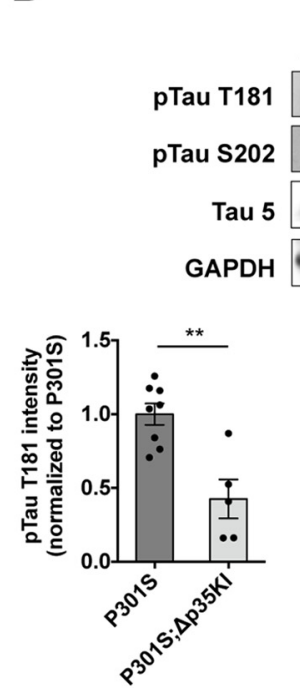

C

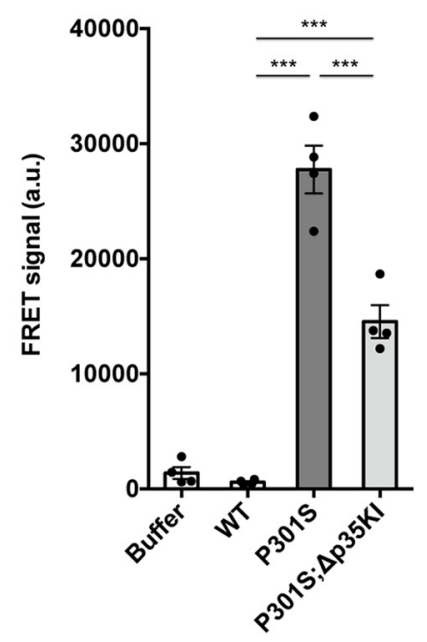

Figure 2. Inhibition of $\mathrm{p} 25 / \mathrm{Cdk} 5$ attenuates hyperphosphorylation of tau and its seeding activity in $P 3015$ mice brain. $A$, Immunohistochemistry with an anti-pTau T181 antibody in hippocampal CA1 of WT, P301S, and P301S; $\Delta$ p35KI mice. Scale bar, $20 \mu \mathrm{m}$. B, Relative levels of pTau T181, pTau S202, and total tau in P301S and P301S; $\Delta p 35 \mathrm{KI}$ hippocampus normalized to P301S ( $n=4-8$, per group; Student's $t$ test). C, Cortical lysates from 2-month-old WT, P301S, and P301S; $\Delta p 35 \mathrm{KI}$ mice were added to biosensor HEK293T cells, and their tau seeding activity was quantified by measuring FRET signals ( $n=4$ per group; $p<0.0001$ by ANOVA). ${ }^{*} p<0.05$ (Student's $t$ test or Tukey's post hoc analysis). ${ }^{* *} p<0.01$ (Student's $t$ test or Tukey's post hoc analysis). ${ }^{* * *} p<0.001$ (Student's $t$ test or Tukey's post hoc analysis). Error bars indicate \pm SEM.

region of $P 301 S$ mice by 3 months of age (Yoshiyama et al., 2007). To address the effect of p25/Cdk5 inhibition on pathogenic taumediated synaptic loss, we measured synaptic density using an anti-synaptophysin antibody in the CA3 region of 4-month-old P301S, P301S; $\Delta$ p35KI, and WT littermate mice. Consistent with previous observations, $P 301 S$ mice showed significantly reduced levels of synaptophysin in CA3 compared with their WT littermates (Fig. $3 A$ ). We also observed a trend toward to a reduction of synaptophysin levels in CA1 of P301S mice compared with WT, although it was not statistically significant (data not shown). This synaptic loss in CA3 was completely reversed to the levels of WT by inhibiting $\mathrm{p} 25$ generation (Fig. $3 A ; p=0.0005$ by ANOVA). To functionally analyze synapse integrity, we next performed extracellular field recordings to measure synaptic strength and LTP at mossy fiber-CA3 synapses. We observed that, while basal synaptic transmission in P301S mice was reduced compared with WT controls, inhibition of p25 in P301S mice significantly rescued this effect. Importantly, neither $\Delta p 35 K I$ mice nor P301S; $\Delta p 35 K I$ mice exhibited different basal synaptic transmission compared with controls. The reduced baseline transmission in P301S mice seems to be due to a reduction of synapse number rather than an alteration of presynaptic neurotransmitter release because paired-pulse facilitation ratios were not different between P301S and WT mice (Fig. 3B). Consistent with the loss of synaptic density, P301S mice did not show any potentiation of fEPSPs after three high-frequency stimulations. However, similar to control and $\Delta p 35 \mathrm{KI}$ mice, P301S; $\Delta$ p35KI mice showed $\sim 150 \%$ potentiation of fEPSP by the stimulations (Fig. $3 C ; p=0.0013$ by ANOVA), indicating the restoration of synaptic plasticity by $\mathrm{p} 25$ inhibition in P301S mice.

Inhibition of p25 generation reduces the levels of pTau in human cerebral organoids carrying a P301L mutation in tau To validate the effect of p 25 generation on tau hyperphosphorylation in human model systems, we used iPSCs derived from fibroblasts from an FTD patient carrying the Tau P301L mutation. We then derived 3D human cerebral organoids from this
iPSC line (MGH-2046) as well as from the nonmutant control line (MGH-2069) as reported previously (Raja et al., 2016). This system enabled us to address the role of p25 in tau hyperphosphorylation in the context of a different tau mutation associated with tauopathy, as both tau and p35 are highly expressed in neurons. Two-month-old organoids derived from iPSCs carrying the P301L mutation showed higher $\mathrm{p} 25 / \mathrm{p} 35$ protein ratios compared with those derived from the nonmutant control (Fig. $4 A ; p=$ 0.038). To determine the role of $\mathrm{p} 25 / \mathrm{Cdk} 5$ in tau hyperphosphorylation, we generated isogenic lines in which endogenous p35 is replaced with $\Delta \mathrm{p} 35$ protein by targeting Cas9 to the endogenous CDK5R1 locus (encoding p35) alongside a template donor oligonucleotide harboring the $\Delta$ p35 DNA sequence (Fig. $4 B$ ). Sanger sequencing confirmed the incorporation of $\Delta$ p35 sequence into the genome (Fig. 4C). The top three potential off-target sites predicted using CRISPR design tool (http://crispr.mit.edu) were inspected, and sequencing data showed that no off-target effect was present in these regions (data not shown). Two-month-old organoids from P301L iPSCs and P301L; $\Delta$ p35KI isogenic lines were subjected to Western blotting experiments. We first measured the levels of p25 generation in both groups and observed a significant reduction of p25 abundance by this genetic manipulation in human cerebral organoids (Fig. $4 D ; p=0.0092$ ). We then examined the levels of pTau using two different antibodies (pTau S202 and pTau T181) as well as total tau. Consistent with the data from our mouse study, we observed a substantial reduction of pTau levels in P301L; $\Delta$ p35KI organoids compared with P301L organoids (Fig. $4 D ; p=0.002$ for pTau S202, $p<0.0001$ for pTau T181). We also observed a similar reduction in total tau levels $(p=0.0029)$. And there was a trend to $\mathrm{pTau} / \mathrm{total}$ tau being reduced, although it was not statistically significant. These effects on total tau do not appear to result from a reduced number of neurons, as indicated by comparable levels of NeuN $(p=0.94)$, and could instead be due to the reduced aggregation of unphosphorylated versus phosphorylated tau. The expression of synaptophysin was higher in P301L; $\Delta$ p35KI organoids, which is also consistent with the observation from $\Delta p 35 K I$ mice (Fig. $4 D ; p=$ 
A
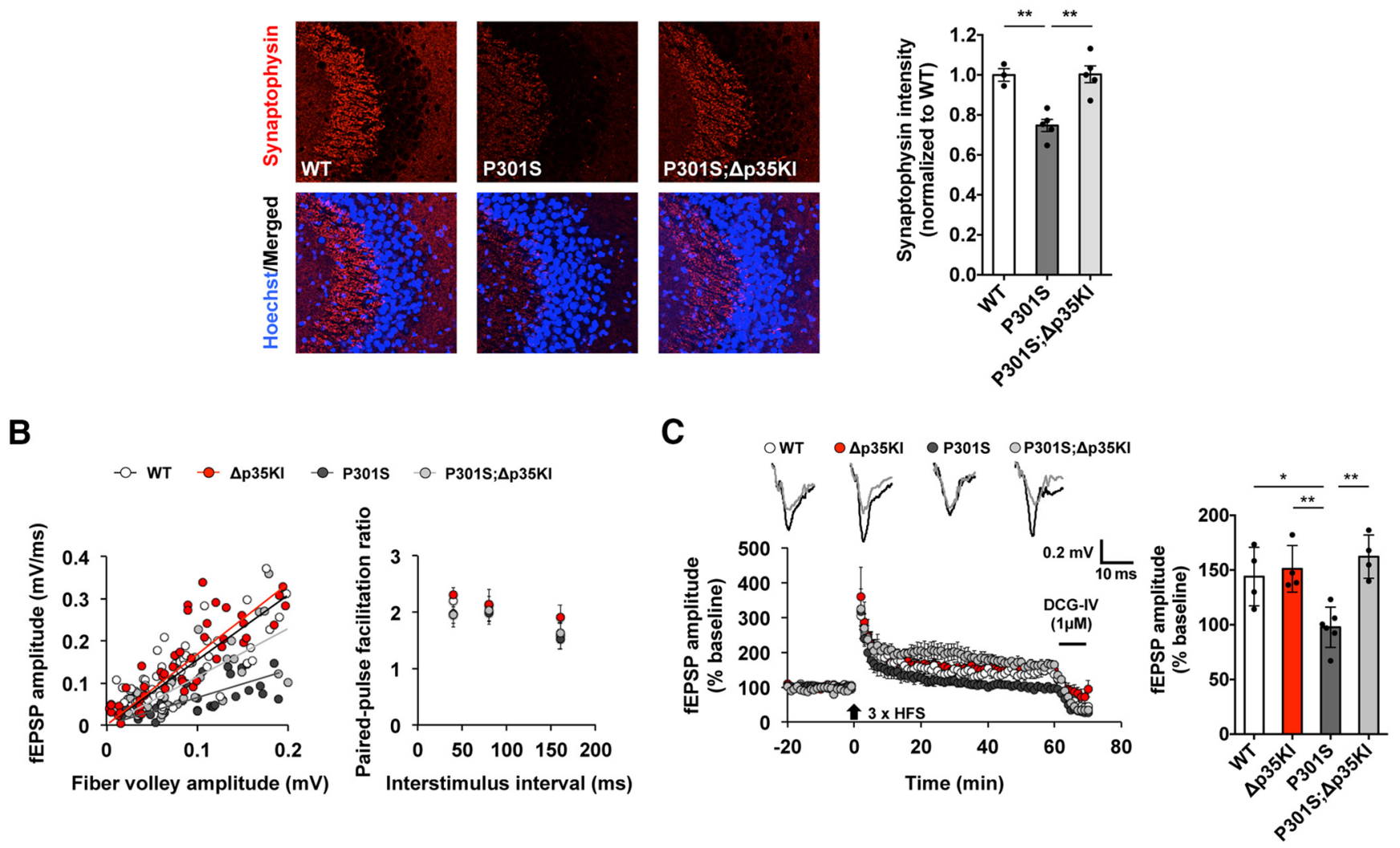

Figure 3. Blockade of p 25 generation restores synaptic integrity and function in hippocampal CA3 region of $P 3015$ mice. $A$, Immunohistochemistry with an anti-synaptophysin antibody in hippocampal CA3 of WT, P301S, and P301S; $\triangle$ p35KI mice. Right, Bar graphs represent the relative immunoreactivity of synaptophysin in WT, $P 3015$, and P3015; $\Delta p 35 \mathrm{~K} / \mathrm{normalized} \mathrm{to} \mathrm{WT}(n=3-5$ per group; $p=0.0005$ by ANOVA). Scale bar, $20 \mu \mathrm{m} . B$, Left, Input- output curves from the fEPSP amplitude against the fiber volley amplitude at a range of stimulus intensities. Right, Paired-pulse facilitation (fEPSP2/fEPSP1) was measured at various interstimulus intervals. C, LTP was induced by $3 \times$ high-frequency stimulation at mossy fiber-CA3 synapses. Sample traces represent $\mathrm{fEPSP}$ at $1 \mathrm{~min}$ before (gray) and $1 \mathrm{~h}$ after (block) high-frequency stimulation. Calibration: $0.2 \mathrm{mV}, 10 \mathrm{~ms}$. Right, The magnitude of LTP was calculated by comparing the average slopes of fEPSPs during the last 5 min of recordings with those recorded before stimulation ( $n=4-6$ per group; $p=0.0013$ by ANOVA). ${ }^{*} p<0.05$ (Student's $t$ test or Tukey's post hoc analysis). ${ }^{* *} p<0.01$ (Student's $t$ test or Tukey's post hoc analysis). Error bars indicate \pm SEM.

0.0287). Immunofluorescence analysis of the cerebral organoids also confirmed a reduction of pTau levels in P301L organoids by inhibition of p25 (Fig. $4 E ; p=0.023$ ). These data provide the first demonstration in a human neuronal culture system that disruption of p25/Cdk5 activity can ameliorate tauopathy phenotypes.

\section{Discussion}

Whereas the relationship between $\mathrm{p} 25 / \mathrm{Cdk} 5$ and amyloid pathology has been an active area of interest, the impact of 252 inhibition upon another hallmark of $\mathrm{AD}$, tauopathy, is less clear. Cdk5 hyperactivation by overexpressing $\mathrm{p} 25$ was shown to induce tauopathy in mouse brains (Cruz et al., 2003; Noble et al., 2003). However, the contribution of p25/Cdk5 complex to the development of tauopathy under pathological conditions by loss-of-function study has not been investigated. In this study, by genetically abolishing $\mathrm{p} 25$ generation, we have attempted to address whether p 25 generation is necessary for aspects of tau-associated pathologies.

In the brain of P301S mice, a model of FTD, we found that p25/Cdk5 inhibition significantly reduces hyperphosphorylation of tau and its seeding activity. The levels of pTau and tau seeding activity in P301S; $\Delta$ p35KI mice are still higher than those of WT mice because these mice significantly overexpress P301S tau. However, we found that inhibition of p25 generation is sufficient to restore synaptic integrity and function in this animal. To further determine the role of p25/Cdk5 in mutant tau-mediated pathology in human neurons, we turned to iPSC systems. Previous studies showed that human neurons differentiated from iPSCs of FTD patients carrying mutations in tau expressed higher levels of pTau and total tau compared with those from unaffected individuals (Fong et al., 2013; Silva et al., 2016). This effect does not appear to be due to increased number of neurons by early maturation because the levels of neuronal markers were not affected. These data showed that pathogenic mutant tau induced hyperphosphorylation of tau as well as accumulation of total tau, which could be caused by abnormal protein folding and impaired clearance of this pathogenic protein. Using the CRISPR/Cas9 genome-editing technique, we have created isogenic lines of human iPSCs derived from an FTD patient carrying a P301L mutation in the MAPT gene, with endogenous p35 replaced with $\Delta \mathrm{p} 35$. Cerebral organoids derived from these isogenic iPSC lines demonstrated that blockade of $\mathrm{p} 25$ production reduced tau phosphorylation on multiple epitopes as well as lowering total tau. As noted above, the effect on total tau levels could be due to enhanced clearance of unphosphorylated tau. It is important to note that we did not observe such a reduction of total tau in P301S; $\Delta$ p 35KI mice compared with P301S mice. This discrepancy could be from characteristics of two different model systems. Unlike cerebral organoids that express endogenous levels of mutant tau, P301S mice overexpress mutant tau at levels more than fivefold higher than endogenous tau. This could lower the 
A

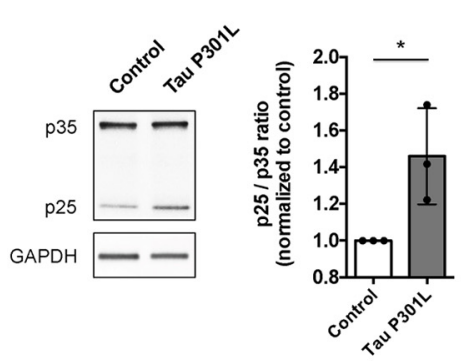

B

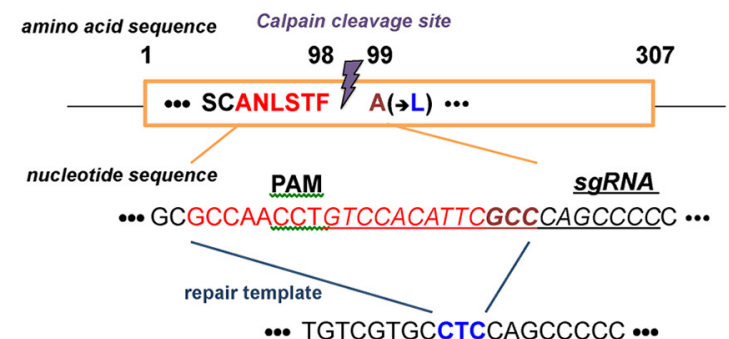

C

Tau P301L

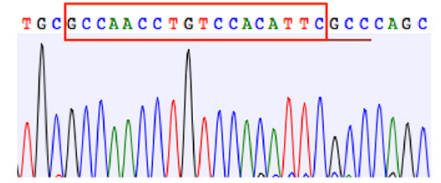

Tau P301L; $\Delta$ p35KI

TGCCTCCAGC

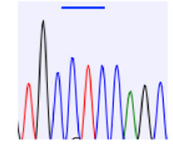

D

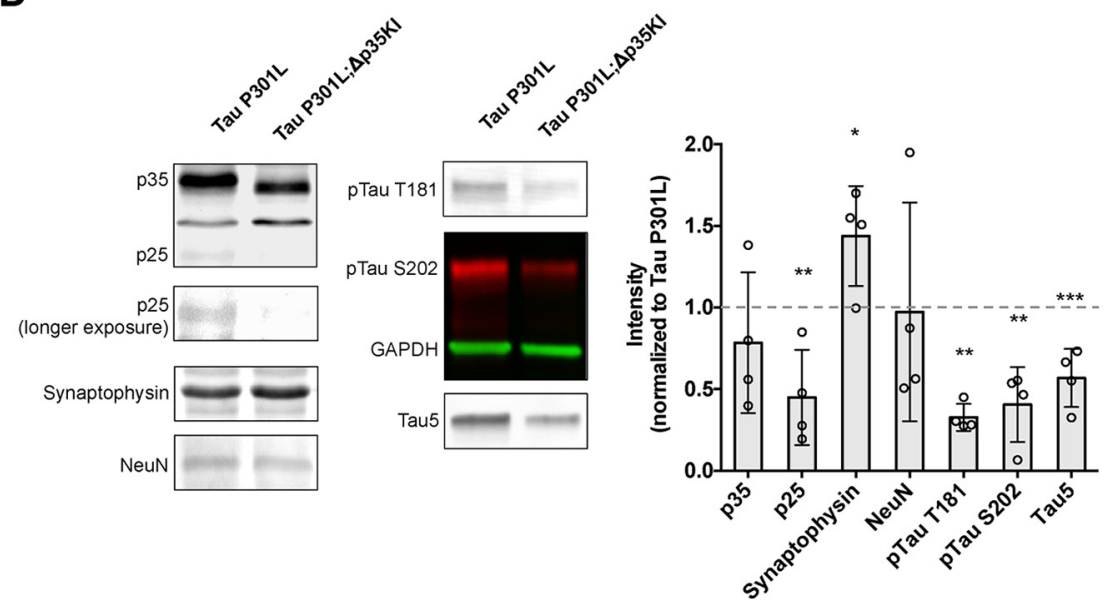

E

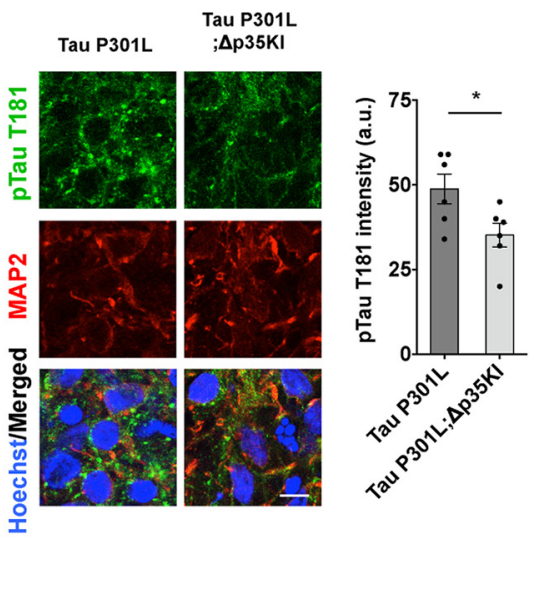

Figure 4. pTau levels in organoids derived from an FTD patient iPSCs are reduced by inhibition of p25 expression. $\boldsymbol{A}$, Relative levels of $\mathrm{p} 35$ and p25 in organoids derived from nonmutant control (MGH 2069) or Tau P301L (MGH 2046) iPSCS ( $n=3$ biological replicates; 3 or 4 organoids were pooled for each blot). $\boldsymbol{B}$, Schematics of $\Delta$ p35Kl isogenic line generation from an FTD patient iPSCs carrying the Tau P301L mutation. C, Sanger sequencing confirms the insertion of a desired repair template into an FTD patient iPSCs. D, Relative levels of p35, p25, synaptophysin, NeuN, pTau T181, pTau S202, and total tau in organoids derived from P301L or P301L; $\Delta$ p35KI iPSCs. Right, Bar graph represents the quantification of relative immunoreactivity for each protein in organoids normalized to P301L organoids ( $n=4$ biological replicates; 3 or 4 organoids were pooled for each blot). $E$, Immunohistochemistry with an anti-p Tau T181 antibody in organoids derived from P301L or P301L; $\Delta \mathrm{p} 35 \mathrm{KL} \mathrm{I}$ iSCS. Scale bar, $5 \mu \mathrm{m}$. Right, Bar graph represents the relative immunoreactivity of pTau T181 in each group ( $n=6$ per group). ${ }^{*} p<0.05$ (Student'st test). ${ }^{* *} p<0.01$ (Student's $t$ test). ${ }^{* *} p<0.001$ (Student's $t$ test). Error bars indicate \pm SEM.

efficiency to reduce expression of total tau, even though p25 inhibition attenuates hyperphosphorylation of tau.

Interestingly, we observed that inhibition of p25 generation increases levels of synaptophysin in both the P301S mice brain and Tau P301L organoids. Tau is generally localized to the axons of neurons; however, hyperphosphorylated tau accumulates in the somatodendritic compartment. This leads to mislocalization of tau-interacting proteins, such as the Fyn kinase. Previously, it was shown that abnormal expression of Fyn followed by tau mislocalization at the synapse results in the phosphorylation and activation of NMDA receptors, leading to neurotoxicity (Ittner et al., 2010). We showed previously that NMDA receptor activation leads to p25 generation, which subsequently causes synaptic depression (Seo et al., 2014). Therefore, it is conceivable that p25 generation not only facilitates tau hyperphosphorylation by leading to aberrant Cdk5 activation, but also mediates neurotoxicityinduced synaptic depression and subsequent synaptic loss at the synapses of brains with tauopathy.

In the progression of $\mathrm{AD}$, an increase of $\mathrm{A} \beta$ is apparent as much as a couple of decades before the onset of clinical symptoms (Jack et al., 2010). A $\beta$ accumulation is followed by hyperphosphorylation of tau, subsequent neuronal loss, and cognitive impairment. Although this suggests that $\mathrm{A} \beta$ could cause abnormal phosphorylation of tau, the lack of tauopathy in mouse models of amyloidosis is perplexing. One potential explanation is the dif- ferent nature of the tau species in mouse versus humans. Mouse does not express certain tau isoforms; thus, it cannot recapitulate the human four-repeat tau (4R-tau):three-repeat tau (3R-tau) ratio change in which have been associated with the formation of tauopathy (Adams et al., 2010; Schoch et al., 2016). Recent studies using iPSC-derived neurons from $\mathrm{AD}$ patients showed that this human model system nicely recapitulates both upregulation of $\mathrm{A} \beta$ and hyperphosphorylation of tau (Israel et al., 2012; Muratore et al., 2014). Cdk5 is a well-established tau kinase. Because we saw the beneficial effect of p25/Cdk5 inhibition on $\mathrm{A} \beta$ induced pathology in the 5XFAD mouse model (Seo et al., 2014) and on tauopathy in human model systems, we speculate that p25/Cdk5 mediates A $\beta$-induced hyperphosphorylation of tau. And this further increases p 25 generation and Cdk 5 hyperactivation as forming a feedforward loop. p25/Cdk5 could also facilitate tau phosphorylation by other kinases, such as GSK-3 $\beta$ (Kimura et al., 2014). As such, inhibition of p25/Cdk5 would likely be beneficial in this system.

In conclusion, our study, using P301S; $\Delta$ p35KI mice and P301L; $\Delta$ p35KI iPSCs, suggests that inhibition of p25/Cdk5 is effective in ameliorating disease-causing mutant tau-mediated pathology. Therefore, further efforts to develop inhibitors of p25mediated Cdk5 dysregulation are warranted and could benefit both AD and FTD patients. 


\section{References}

Adams SJ, DeTure MA, McBride M, Dickson DW, Petrucelli L (2010) Three repeat isoforms of tau inhibit assembly of four repeat tau filaments. PLoS One 5:e10810. CrossRef Medline

Ahlijanian MK, Barrezueta NX, Williams RD, Jakowski A, Kowsz KP, McCarthy S, Coskran T, Carlo A, Seymour PA, Burkhardt JE, Nelson RB, McNeish JD (2000) Hyperphosphorylated tau and neurofilament and cytoskeletal disruptions in mice overexpressing human p25, an activator of cdk5. Proc Natl Acad Sci U S A 97:2910-2915. CrossRef Medline

Clavaguera F, Bolmont T, Crowther RA, Abramowski D, Frank S, Probst A, Fraser G, Stalder AK, Beibel M, Staufenbiel M, Jucker M, Goedert M, Tolnay M (2009) Transmission and spreading of tauopathy in transgenic mouse brain. Nat Cell Biol 11:909-913. CrossRef Medline

Cruz JC, Tseng HC, Goldman JA, Shih H, Tsai LH (2003) Aberrant Cdk5 activation by $\mathrm{p} 25$ triggers pathological events leading to neurodegeneration and neurofibrillary tangles. Neuron 40:471-483. CrossRef Medline

de Calignon A, Polydoro M, Suárez-Calvet M, William C, Adamowicz DH, Kopeikina KJ, Pitstick R, Sahara N, Ashe KH, Carlson GA, Spires-Jones TL, Hyman BT (2012) Propagation of tau pathology in a model of early Alzheimer's disease. Neuron 73:685-697. CrossRef Medline

Fong H, Wang C, Knoferle J, Walker D, Balestra ME, Tong LM, Leung L, Ring KL, Seeley WW, Karydas A, Kshirsagar MA, Boxer AL, Kosik KS, Miller BL, Huang Y (2013) Genetic correction of tauopathy phenotypes in neurons derived from human induced pluripotent stem cells. Stem Cell Reports 1:226-234. CrossRef Medline

Frost B, Jacks RL, Diamond MI (2009) Propagation of tau misfolding from the outside to the inside of a cell. J Biol Chem 284:12845-12852. CrossRef Medline

Hashiguchi M, Saito T, Hisanaga S, Hashiguchi T (2002) Truncation of CDK5 activator p35 induces intensive phosphorylation of Ser202/Thr205 of human tau. J Biol Chem 277:44525-44530. CrossRef Medline

Holmes BB, Furman JL, Mahan TE, Yamasaki TR, Mirbaha H, Eades WC, Belaygorod L, Cairns NJ, Holtzman DM, Diamond MI (2014) Proteopathic tau seeding predicts tauopathy in vivo. Proc Natl Acad Sci U S A 111:E4376-E4385. CrossRef Medline

Israel MA, Yuan SH, Bardy C, Reyna SM, Mu Y, Herrera C, Hefferan MP, Van Gorp S, Nazor KL, Boscolo FS, Carson CT, Laurent LC, Marsala M, Gage FH, Remes AM, Koo EH, Goldstein LS (2012) Probing sporadic and familial Alzheimer's disease using induced pluripotent stem cells. Nature 482:216-220. CrossRef Medline

Ittner LM, Ke YD, Delerue F, Bi M, Gladbach A, van Eersel J, Wölfing H, Chieng BC, Christie MJ, Napier IA, Eckert A, Staufenbiel M, Hardeman E, Götz J (2010) Dendritic function of tau mediates amyloid-beta toxicity in Alzheimer's disease mouse models. Cell 142:387-397. CrossRef Medline

Jack CR Jr, Knopman DS, Jagust WJ, Shaw LM, Aisen PS, Weiner MW, Petersen RC, Trojanowski JQ (2010) Hypothetical model of dynamic biomarkers of the Alzheimer's pathological cascade. Lancet Neurol 9:119-128. CrossRef Medline

Kimura T, Ishiguro K, Hisanaga S (2014) Physiological and pathological phosphorylation of tau by Cdk5. Front Mol Neurosci 7:65. CrossRef Medline

Kolarova M, García-Sierra F, Bartos A, Ricny J, Ripova D (2012) Structure and pathology of tau protein in Alzheimer disease. Int J Alzheimers Dis 2012:731526. CrossRef Medline

Komor AC, Badran AH, Liu DR (2017) CRISPR-based technologies for the manipulation of eukaryotic genomes. Cell 168:20-36. CrossRef Medline

Kondadi AK, Wang S, Montagner S, Kladt N, Korwitz A, Martinelli P, Herholz D, Baker MJ, Schauss AC, Langer T, Rugarli EI (2014) Loss of the m-AAA protease subunit $\mathrm{AFG}_{3} \mathrm{~L}_{2}$ causes mitochondrial transport defects and tau hyperphosphorylation. EMBO J 33:1011-1026. CrossRef Medline

Kusakawa G, Saito T, Onuki R, Ishiguro K, Kishimoto T, Hisanaga S (2000) Calpain-dependent proteolytic cleavage of the p35 cyclin-dependent kinase 5 activator to p25. J Biol Chem 275:17166-17172. CrossRef Medline

Lee MS, Kwon YT, Li M, Peng J, Friedlander RM, Tsai LH (2000) Neurotoxicity induces cleavage of p35 to p25 by calpain. Nature 405:360-364. CrossRef Medline

Mazanetz MP, Fischer PM (2007) Untangling tau hyperphosphorylation in drug design for neurodegenerative diseases. Nat Rev Drug Discov 6:464479. CrossRef Medline

Miller N, Feng Z, Edens BM, Yang B, Shi H, Sze CC, Hong BT, Su SC, Cantu JA, Topczewski J, Crawford TO, Ko CP, Sumner CJ, Ma L, Ma YC (2015) Non-aggregating tau phosphorylation by cyclin-dependent kinase 5 contributes to motor neuron degeneration in spinal muscular atrophy. J Neurosci 35:6038-6050. CrossRef Medline

Mou X, Wu Y, Cao H, Meng Q, Wang Q, Sun C, Hu S, Ma Y, Zhang H (2012) Generation of disease-specific induced pluripotent stem cells from patients with different karyotypes of Down syndrome. Stem Cell Res Ther 3:14. CrossRef Medline

Muratore CR, Rice HC, Srikanth P, Callahan DG, Shin T, Benjamin LN, Walsh DM, Selkoe DJ, Young-Pearse TL (2014) The familial Alzheimer's disease APPV717I mutation alters APP processing and Tau expression in iPSC-derived neurons. Hum Mol Genet 23:3523-3536. CrossRef Medline

Nath R, Davis M, Probert AW, Kupina NC, Ren X, Schielke GP, Wang KK (2000) Processing of cdk5 activator p35 to its truncated form (p25) by calpain in acutely injured neuronal cells. Biochem Biophys Res Commun 274:16-21. CrossRef Medline

Noble W, Olm V, Takata K, Casey E, Mary O, Meyerson J, Gaynor K, LaFrancois J, Wang L, Kondo T, Davies P, Burns M, Veeranna, Nixon R, Dickson D, Matsuoka Y, Ahlijanian M, Lau LF, Duff K (2003) Cdk5 is a key factor in tau aggregation and tangle formation in vivo. Neuron 38:555-565. CrossRef Medline

Patrick GN, Zukerberg L, Nikolic M, de la Monte S, Dikkes P, Tsai LH (1999) Conversion of p35 to p25 deregulates Cdk5 activity and promotes neurodegeneration. Nature 402:615-622. CrossRef Medline

Piedrahita D, Hernández I, López-Tobón A, Fedorov D, Obara B, Manjunath BS, Boudreau RL, Davidson B, Laferla F, Gallego-Gómez JC, Kosik KS, CardonaGómez GP (2010) Silencing of CDK5 reduces neurofibrillary tangles in transgenic alzheimer's mice. J Neurosci 30:13966-13976. CrossRef Medline

Raja WK, Mungenast AE, Lin YT, Ko T, Abdurrob F, Seo J, Tsai LH (2016) Self-organizing 3D human neural tissue derived from induced pluripotent stem cells recapitulate Alzheimer's disease phenotypes. PLoS One 11:e0161969. CrossRef Medline

Ran FA, Hsu PD, Wright J, Agarwala V, Scott DA, Zhang F (2013) Genome engineering using the CRISPR-Cas9 system. Nat Protoc 8:2281-2308. CrossRef Medline

Rao MV, McBrayer MK, Campbell J, Kumar A, Hashim A, Sershen H, Stavrides PH, Ohno M, Hutton M, Nixon RA (2014) Specific calpain inhibition by calpastatin prevents tauopathy and neurodegeneration and restores normal lifespan in tau P301L mice. J Neurosci 34:9222-9234. CrossRef Medline

Schoch KM, DeVos SL, Miller RL, Chun SJ, Norrbom M, Wozniak DF, Dawson HN, Bennett CF, Rigo F, Miller TM (2016) Increased 4R-tau induces pathological changes in a human-tau mouse model. Neuron 90 : 941-947. CrossRef Medline

Seo J, Giusti-Rodríguez P, Zhou Y, Rudenko A, Cho S, Ota KT, Park C, Patzke H, Madabhushi R, Pan L, Mungenast AE, Guan JS, Delalle I, Tsai LH (2014) Activity-dependent p25 generation regulates synaptic plasticity and $\mathrm{A} \beta$ induced cognitive impairment. Cell 157:486-498. CrossRef Medline

Siegert S, Seo J, Kwon EJ, Rudenko A, Cho S, Wang W, Flood Z, Martorell AJ, Ericsson M, Mungenast AE, Tsai LH (2015) The schizophrenia risk gene product miR-137 alters presynaptic plasticity. Nat Neurosci 18:10081016. CrossRef Medline

Silva MC, Cheng C, Mair W, Almeida S, Fong H, Biswas MH, Zhang Z, Huang Y, Temple S, Coppola G, Geschwind DH, Karydas A, Miller BL, Kosik KS, Gao FB, Steen JA, Haggarty SJ (2016) Human iPSC-derived neuronal model of tauA152T frontotemporal dementia reveals tau-mediated mechanisms of neuronal vulnerability. Stem Cell Reports 7:325-340. CrossRef Medline

Van den Haute C, Spittaels K, Van Dorpe J, Lasrado R, Vandezande K, Laenen I, Geerts H, Van Leuven F (2001) Coexpression of human cdk5 and its activator p35 with human protein tau in neurons in brain of triple transgenic mice. Neurobiol Dis 8:32-44. CrossRef Medline

Yoshiyama Y, Higuchi M, Zhang B, Huang SM, Iwata N, Saido TC, Maeda J, Suhara T, Trojanowski JQ, Lee VM (2007) Synapse loss and microglial activation precede tangles in a P301S tauopathy mouse model. Neuron 53:337-351. CrossRef Medline

Zhang X, Hernandez I, Rei D, Mair W, Laha JK, Cornwell ME, Cuny GD, Tsai LH, Steen JA, Kosik KS (2013a) Diaminothiazoles modify Tau phosphorylation and improve the tauopathy in mouse models. J Biol Chem 288:22042-22056. CrossRef Medline

Zhang Z, Almeida S, Lu Y, Nishimura AL, Peng L, Sun D, Wu B, Karydas AM, Tartaglia MC, Fong JC, Miller BL, Farese RV Jr, Moore MJ, Shaw CE, Gao FB (2013b) Downregulation of microRNA-9 in iPSC-derived neurons of FTD/ALS patients with TDP-43 mutations. PLoS One 8:e76055. CrossRef Medline 